\title{
Prospects and Problems in Modeling Group Decisions
}

\author{
JOEL H. STECKEL \\ KIM P. CORFMAN \\ New York University \\ DAVID J. CURRY \\ University of Cincinnati \\ SUNIL GUPTA \\ University of Michigan \\ JAMES SHANTEAU \\ National Science Foundation
}

500 Tisch Hall, New York University, 40 West 4th Street, New York, New York I0003

Key words: Group Decision Modeling, Group Choice Models

\begin{abstract}
This paper summarizes some of the major issues related to group decision modeling. We briefly review the existing work on group choice models in marketing and consumer research. We draw some gencralizations about which models work well when and use thosc generalizations to provide guidelines for future research.
\end{abstract}

Groups pervade virtually every aspect of our lives. We belong to families, work cohorts, clubs, church groups, and professional organizations among others. We do many things in groups too. We make decisions; we travel; we play games; we work; we consume. In the early 1970s, researchers in marketing and consumer decision making realized through studying families and organizational buying centers that the group was an important unit of analysis (Davis 1970, 1976; Webster and Wind 1972). It was not until almost a decade later that we, as a discipline, started to propose and test formal models of group decision making.

This paper summarizes some major issues related to group decision modeling. The major questions addressed include "What have we done," "What have we learned?" "What do we need to do to learn more?" and "How do we go about learning?" In the past decade or so a fair amount of effort has been exerted in the proposal and empirical testing of group choice models. By and large, each model worked quite well in the setting in which it was tested. However, it seems that no single class of models is appropriate for all problems. "What we have done" then is propose and test a wide variety of group choice models. "What we have learned" is that each model seems to work well in the setting for which it was 
designed. Consequently, we have gained some preliminary insight as to which models work well when. Further resolution of this issue awaits the development of future models. Clearly, new models we develop will work well in situations current models do not. "What we have to do" then is continue to develop new models and refine the answers to the "which model works well when question."

This paper begins by briefly reviewing the group choice modeling literature in marketing/consumer choice. We then draw generalizations about the conditions under which certain models may be most appropriate. These characterizations are inferred from the experimental results reported in the literature. We next suggest what types of models need to be pursued and propose specific guidelines for where to look for them. The paper concludes with a brief discussion of data collection issues.

\section{Group choice models in marketing}

The first formal group choice modeling efforts in marketing were those of Choffray and Lilien (1976: 1980). Borrowing from Davis's (1973) Social Decision Scheme theory, they proposed four different models, each of which corresponds to a different conceptualization of the interaction mechanism within groups. Individual choice probabilities are mapped into group choice probabilities by an algebraic rule which reflects the nature of how groups decide (e.g. vote, choose a member at random to make the decision, look for a minimum number of members to approve of an alternative, or look for an alternative that least perturbs the preferences of all the group members). The Choffray and Lilien models are relatively unique in the marketing literature in their focus on the interaction mechanism. Most of the others simply focus on predicting outcomes and consequently are accompanied by an empirical test of some sort.

There appear to be two categories of predictive models in the literature, paramorphic linear and normative. Linear models were first introduced simply as paramorphic predictive tools. Groups were assumed to behave as if they followed a linear model. It did not matter that groups did not actually behave according to a linear model; it only mattered that the linear model predicted well. It should be noted that paramorphic models do not need to be linear. It just happens that most of the models we use are. In contrast, the original intent behind normative models was to describe behavior that reasonable, rational people should follow. This may be very different from describing what people actually do. However, to the extent that people subscribe to the rational underpinnings of the normative models, these models can describe what people actually do. Thus, they are also potential predictive tools.

In a very important sense, however, the distinction between linear and normative models is artificial. There is a normative characterization of the linear model. (cf. Keeney and Kirkwood 1975; Keeney and Raiffa 1976). However, with two 
exceptions (Eliashberg et. al. 1986; Rao and Steckel, forthcoming), those who have used these models simply use linear models in a paramorphic sense.

\subsection{Linear models}

Linear models of group choice represent a group's preference as a weighted sum of the individual's preferences. Although these models have used different measures of preference (e.g. utility, choice probability), the interesting components of these models are the weights themselves and not what they combine.

Early in this stream, a number of authors suggested that equal weights be used as a starting point. Curry and Menasco (1979) prove that equal weights result in a group (husband-wife dyad in their case) selecting the alternative that maximizes their total joint utility. Krishnamurthi (1981) performed an experiment in which equal weight models predicted quite well relative to those that were differentially weighted.

Nevertheless, equal weights assume that all group members have equal impacts on the outcomes of a group's decision. This is simply not true in most cases. Therefore, other researchers have turned their attention toward finding more reliable ways to estimate differential weights (cf. Steckel, Lehmann, and Corfman 1988; Steckel and O'Shaughnessy 1989) or uncovering the factors which differentiate the weights (Corfman and Lehmann 1987; Rao and Steckel, forthcoming). These efforts have all shown significant predictive improvements over the equal weight model.

Linear models have been tested in a wide variety of contexts; M.B.A. and spouse job choices (Krishnamurthi 1981), husband-wife durable and service choices (Corfman and Lehmann 1987), ad-hoc dyads' selections of music pieces and common stocks (Steckel, Lehmann, and Corfman 1988), organizational buying behavior (Steckel and O'Shaughnessy 1989), marketing faculty choosing among potential hires and undergraduates deciding on restaurants (Rao and Steckel, forthcoming), and a manufacturer-retailer negotiation experiment (Eliashberg et.al. 1986). In all cases, linear models appeared to achieve an acceptable level of performance.

\subsection{Normative models}

Normative models of group choice postulate sets of principles which reflect fairness and/or efficiency. Model builders argue that group choices, preferences, choice probabilities, and utility functions should follow these principles. The principles are mathematicized as axioms so that a solution characterized by them can be derived in an analytically elegant way. Of course the precise solution depends on the original set of principles (axioms). However all solutions retain the nor- 
mative spirit. They determine 'correct' or "appropriate' decisions. Thus, these solutions provide a reasonable benchmark for descriptive modeling.

Most marketers who have studied group choices and explicitly recognized normative traditions have borrowed their models from the theory of cooperative games. The theory of cooperative games can be divided into the two-person bargaining problem and the more general $\mathrm{n}$-person game.

The most prominent effort in the bargaining literature is that of Nash (1950). The conflict point, sometimes called the no settlement point or status quo, is an integral concept to Nash's theory. This point is a default outcome which the bargainers must accept if they are unable to reach an agreement. Nash proposed the following set of axioms that the outcome should obey (cf. Luce and Raiffa 1957, pp. 124-134; Neslin and Greenhalgh 1983, p. 370):

1. Individual Rationality - Both players should be better off at the outcome than they would at the conflict point;

2. Feasibility - The outcome should be chosen from the set of possible outcomes of the negotiation;

3. Independence of Utility Function Scale - The outcome should not depend on how utility is measured;

4. Pareto Optimality - No other settlement which both bargainers prefer should exist;

5. Independence of Irrelevant Alternatives - If X is the outcome of a bargaining situation, it should also be the outcome of any situation where the possible outcomes are a subset (including $\mathrm{X}$ ) of the original ones; and

6. Symmetry - If the set of feasible outcomes is symmetric (i.e. if one alternative has a utility distribution $a, b$ for the two bargainers, than another has a distribution $b, a)$, then the outcomes will provide both bargainers with equal utility.

These imply that the solution be the Pareto optimal outcome that maximizes the product of each party's gains over the conflict point. Other solution concepts have modified Nash; but all use his framework as a point of departure (cf. Gupta and Livne 1988; Kalai and Smordinsky 1975).

Neslin and Greenhalgh $(1983 ; 1986)$ tested the predictive validity of the Nash bargaining scheme in a simulated media purchase. They found (1983) that Nash's theory predicts very well in the aggregate. However, when applied to individual dyads, the theory only predicted 42 percent of the outcomes (1986). Furthermore, Neslin and Greenhalgh could not find any effect of situational power or bargaining skill on the outcomes of bargaining situations. They did find, however, that Nash's solution was more predictive when subjects viewed the negotiation as a one-shot deal rather than as a continuing relationship. They also found that Nash solutions were reached more often when the seller was on commission.

Only one study has appeared to this point which employs the more general $n$ person theory. Steckel (1990) tested one solution concept from this literature, the Core (the set of alternatives which cannot be defeated by any other in a simple 
majority rule vote), in a mergers and acquisitions majority rule experiment. He found it to predict quite well.

Game theory experiments are traditionally tailored to the solution concept they are testing. Neslin and Greenhalgh's experiments are explicitly set up as bargaining situations. Steckel informed his subjects that any decision endorsed by a majority of the group would be accepted. The interpretations of the experimental results are usually framed as "The model works in settings for which it is appropriate." In contrast, experiments which test linear models are usually very vague in structure. Group members are left to their own devices to come up with a decision. This is not so much a criticism of game theory models and experiments as it is a testimony to the robustness of linear models.

\section{Which model works when and why?}

In essence, this the main question we need to answer in future years. We are at a point of development where we can make preliminary generalizations about answers to some aspects of this question and assert strong hypotheses about others.

Hypothesis: Linear models work well in almost all circumstances.

This is well-known in individual choice (cf. Johnson and Meyer 1984); but the statement is no less valid in group choice (Corfman and Lehmann 1987; Curry and Menasco 1979; Menasco and Curry 1989; Rao and Steckel, forthcoming; and Steckel, and Lehmann and Corfman 1988).

Dawes and Corrigan (1974) suggest certain conditions under which linear models provide adequate representations. These include: "(a) each input variable has a conditionally monotone relationship with the output; (b) there is error of measurement; and (c) deviations from optimal weighting do not make much practical difference (p.95)." These conditions all apply to the group decision problem. Condition (a) holds if, whenever an individual within a group is more favorably disposed towards an alternative, the group will be too. While this might not hold in every case (e.g. an obnoxious member who offends the remainder of the group), it certainly does in the vast majority. Condition (b) holds as along as we are saddled with imperfections in our preference measures (which we probably always will be). Finally, condition (c) will only be violated when the individuals within a group have negatively correlated preferences. This will occur in any problem that can be modelled as a zero-sum game. However, if there is some degree of agreement within a group, almost any linear combination of member utilities will produce the same ordering.

Examination of condition (c) also demonstrates why equal weights work reasonably well in predicting group judgments (Einhorn, Hogarth, and Klemperer 1979). Rarely will there be total and complete disagreement among group members. And even in those cases in which it does occur, equal weighting prohibits "mistakes"; i.e. placing more weight on the less important individual.

For all their success however, linear models are far from the final word. We 
know this empirically. In experiments directly comparing them to Nash's bargaining scheme (Eliashberg et. al. 1986) and the Core, from cooperative game theory (Steckel 1990), linear models came out second best. The reasons for this have been alluded to previously. Like Neslin and Greenhalgh (1983, 1986), Eliashberg et. al.'s experiment was explicitly designed to be a bargaining one. Steckel's experiments were constructed to examine majority rule decisions, those for which the Core is best designed. Thus, 'The model works in settings for which it is appropriate' conclusion applies. We therefore make the following assertion.

Assertion: If group decisions have a formal structure (e.g. bargaining, majority rule, etc.), models that account for this structure will outpredict those that do not.

Linear models suffer from the limitation that they ignore some fundamental behavioral aspects of group decision making that have been discovered through behavioral research (Hare 1976), such as informational influences or social comparisons. They are therefore limited in their ability to describe and explain group processes. It follows then that (new) models which incorporate these phenomena should have an advantage in prediction (Menasco and Curry 1989).

This is implicit in Choffray and Lilien's $(1976,1980)$ reliance on specific interaction mechanisms in their modeling efforts.

Assertion: Models which incorporate behavioral reality should outpredict those that do not.

The behavioral phenomena to be included will usually depend on the domain of the decision process being studied (e.g. role structure may be important in certain situations where individuals differ in terms of their expertise about separate aspects of the decision). Certain group decision making phenomena, however, are quite pervasive. For example, extensive evidence exists that group discussion generally produces attitudes which are more extreme in the direction of the average of the prediscussion attitudes in a wide variety of situations. This phenomenon is called the group polarization hypothesis (Myers and Lamm 1976). Rao and Steckel (forthcoming) have modified the linear model to account for potential polarization. They demonstrate the superiority of the modified model.

Principle 3 is also illustrated in the bargaining literature. For example, the Gupta-Livne (1988) bargaining model adds some prominent "reference" outcome that can have an effect on the outcome. This is analogous to the no settlement conflict point in the Nash solution. The different is that it is an obvious settlement which can be adopted which leaves both parties better off. Indeed, Gupta and Livne (1990) have shown in a buyer-seller bargaining experiment that, when such a point exists, the Gupta-Livne solution outpredicts the Nash solution.

\section{Future directions}

The future of group choice modeling can be inferred from the three conclusions above. Linear models work (conclusion 1). But how can we improve upon them? The answer we suggest here is either by tailoring the model to the type of decision 
being studied (conclusion 2) or by building models that incorporate empirically observed behavioral realities (conclusion 3 ). The wide variety of decisions with which groups are faced and the plethora of phenomena observed by behavioral scientists suggest that the small library of models we have accumulated is only a beginning. We need more.

Where will these new models come from? Two possibilities exist. We can either borrow them or build them ourselves. We have had great success by borrowing up to this point. Linear models came from social psychology. Bargaining models came from economics and mathematics. Certainly, we have not exhausted the social sciences. They have models and approaches which explicitly account for the type of decision and/or behavioral reality. Two examples are the economic theory of teams and case-based reasoning.

The economic theory of teams (Marschak and Radnor 1972) is an example of an approach that accounts for type of decision. In this theory, a team is a group of persons who must make a set of decisions to further their common interests. Furthermore, the members of the team have no interests besides the common ones. In operational terms, they all subscribe to the same payoff or utility function. Team theory's strength is that it concentrates on three main issues: (1) what information should team members collect about their 'uncertain' environment, (2) whether and how they should communicate this information to their colleagues, and (3) how each individual should react to the information he/she receives (MacCrimmon 1974).

The team theory framework seems to provide a viable approach to modeling a strategic planning committee. A forecasting specialist may make judgments about the growth rates of various markets, a finance specialist can make sure that all sources and uses of funds balance, and a lawyer can comment on the legal ramifications of a strategy. Each committee member would require a different set of information and take a different (set of) action(s). The critical factor in this group situation is the lack of conflict of interest. In principle, each member of the committee is in focussed on the goal of maximizing long term profits for the firm. In practice, however, the team approach may break down if individuals have their own hidden agendas.

Behavioral reality can be incorporated through artificial intelligence procedures which systematically represent the steps in human information processing. One such approach called case-based reasoning (CBR) has been developed by psychologists and computer scientists. Groups use their experiences in previous situations to aid them in current decisions. CBR models decisions in this way (cf. Kolodner 1984; 1990). The central focus is the retrieval of analogous cases (experiences) for use in decision making as opposed to the implementation of known rules. The CBR research paradigm usually terminates in a computer model that simulates a decision process. Algorithms are created which interpret the problem at hand, recall previous cases, select those that are most relevant, propose an initial 'ballpark' solution, adapt it, and justify, criticize, and evaluate the result. Finally, the current situation is added to the library of experience contained in the 
computer's memory. 'The quality of the resulting model depends on the cases stored in its memory and the adeptness of the algorithms that manipulate the case information.

Certainly application of approaches such as team theory and CBR to consumer and marketing group decision making problems would constitute viable research projects. We should not, however, be constrained by the models available in other literatures. The situations and phenomena we model do not necessarily have analogs in other literatures. It would be foolish to dismiss prior work from other disciplines as a guide in this task. Two recent efforts (Gupta and Livne 1989; Rao and Steckel, forthcoming) have taken existing models and modified them to explicitly account for the phenomena they were interested in. This may continue to be a fruitful path. But as marketers and consumer researchers, we need to be more creative, to become more oriented to "model building" than simply " model testing." We need to identify situations and phenomena, and build models which explicitly incorporate them.

\section{Other issues}

This paper has focussed on modeling issues. Modeling, however, is only one of several problems group researchers encounter. One special difficulty they have is how to get good data. The CBR approach is actually more of a data collection procedure than modeling approach since the focus is on the collection and use of data. However, it is not appropriate for all types of model building research. More conventional data sources and collection vehicles are needed. Unfortunately, in vivo groups are virtually impossible to observe. It has also proven difficult to collect more than a very few observations from a group within a single session in a laboratory experiment. Furthermore, the decision process is likely to vary from decision to decision, at least with respect to relative influence (Corfman and Lehmann 1987: Steckel, Lehmann, and Corfman 1988). Therefore, it may be very difficult to collect more than a single observation from any single decision process. Corfman (1990) details a number of other problems with collecting experimental data from groups.

Sources of nonexperimental data would be very valuable to those who wish to model group decision making. One context where this appears to be possible is residential real estate purchasing. Offers and responses tend to be made through third party. In principle, these could be recorded and used to build models and test hypotheses about buyer-seller negotiations. A complete data base might include demographics and prior preferences of the seller, the intermediary, and each family member. The resulting knowledge can be used to either test bargaining models or perhaps even build an expert system for the negotiation process similar in spirit to the CBR approach. 


\section{References}

Choffray, Jean-Marie, and Gary L. Lilien. (1976). "Models of the Multiperson Choice Process with Applications to the Adoption of Industrial Products," M.I.T. Sloan School of Management Working Paper No. 861-76, December.

Choffray, Jean-Marie, and Gary L. Lilien. (1980). Market Planning for New Industrial Products. New York: Wiley.

Corfman, Kim P. (1990). "Methodological Problems in Survey and Experimental Research on Family Choice Processes," Advances in Consumer Research, Vol. XVII, M.E. Goldberg, G. Gorn, and R. Pollay, eds., Provo, UT: Association for Consumer Research, 520-523.

Corfman, Kim P., and Donald R. Lehmann. (1987). "Models of Cooperative Group Decision Making: An Experimental Investigation of Family Purchase Decisions," Journal of Consumer Research 14 (June), 1-13.

Curry, David J., and Michael B. Menasco. (1979). "Some Effects of Different Information Processing Strategies on Husband-Wife Decisions," Journal of Consumer Research 6 (September), 192-203.

Davis, Harry L. (1970). "Dimensions of Marital Roles in Consumer Decision Making," Journal of Marketing Research 7 (May), 168-177.

Davis, Harry L. (1976). "Decision Making in the Household," Journal of Consumer Research 2 (June), 241-260.

Davis, James H. (1973). "Group Decision and Social Interaction," Psychological Review 80 (March), 97-125.

Dawes, Robyn, M., and Bernard Corrigan. (1974). "Linear Models in Decision Making," Psychological Bulletin 81 (February), 95-106.

Einhorn, Hillel J., Robin M. Hogarth, and Eric Klempner. (1977). "Quality of Group Judgments," Psychological Bulletin 84 (January), 158-172.

Eliashberg, Jehoshua, Stephen A. LaTour, Arvind Rangaswamy, and Louis W. Stern. (1986). "Assessing the Predictive Accuracy of Two Utility-Based Theories in a Marketing Channel Negotiation Context," Journal of Marketing Research 23 (May), 101-110.

Gupta, Sunil, and Zvi A. Livne. (1988). "Resolving a Conflict Situation with a Reference Outcome: An Axiomatic Model," Management Science 34 (November), 1303-1314.

Gupta, Sunil, and Zvi A. Livne. (1990). "Testing the Emergence and Effect of Reference Outcome in an Integrative Bargaining Situation," Marketing Letters 1 (June), 103-112.

Hare, A. Paul. (1976). Handbook of Small Group Research, 2nd ed., New York: Free Press.

Johnson, Eric J., and Robert J. Meyer. (1984). "Compensatory Choice Models of Noncompensatory Processes: The Effect of Varying Context," Journal of Consumer Research 11 (June), $528-541$.

Kalai, Ehud, and M. Smordinsky. (1975). "Other Solutions to Nash's Bargaining Problem," Econometrica 43, 513-518.

Keeney, Ralph L., and Craig K. Kirkwood. (1975), "Group Decision-Making Using Cardinal Social Welfare Functions," Management Science 22 (December), 430-437.

Keeney, Ralph L., and Howard Raiffa. (1976). Decisions with Multiple Objectives: Preferences, Values, and Tradeoffs, New York: Wiley.

Kolodner, Janet L. (1984). Retrieval and Organizational Strategies in Conceptual Memory: A Computer Model, Hillsdale, NJ: Lawrence Erlbaum Associates.

Kolodner, Janet L. (1990). "An Introduction to Case-Based Reasoning," Working Paper GIT-ICS90/19, Artificial Intelligence Group, College of Computing, Georgia Institute of Technology.

Krishnamurthi, Lakshmanan. (1981). "Modelling Joint Decision Making Through Relative Influence," Unpublished PhD. Dissertation, Stanford University.

Luce, R. Duncan, and Howard Raiffa. (1957). Games and Decisions, New York: Wiley.

MacCrimmon, Kenneth R. (1974). "Descriptive Aspects of Team Theory: Observation, Commu- 
nication and Decision Heuristics in Information Systems," Management Science 20 (June), $1323-1333$.

Marschak, Jacob, and Roy Radnor. (1972). Economic Theory of Teams, New Haven, CT: Yale University Press.

Menasco, Michael B., and David J. Curry. (1989). "Utility and Choice: An Empirical Study of Wife/Husband Decision Making," Journal of Consumer Research 16 (June), 87-97.

Myers, David G., and H. Lamm. (1976). "The Group Polarization Phenomenon," Psychological Bulletin 83, 602-627.

Nash, John F. (1950). "The Bargaining Problem," Econometrica 18, 155-162.

Neslin, Scott A., and Leonard Greenhalgh. (1983). "Nash's Theory of Cooperative Games as a Predictor of the Outcome of Buyer-Seller Negotiations: An Experiment in Media Purchasing." Journal of Marketing Research 20 (November), 368-379.

Neslin, Scott A., and Leonard Greenhalgh. (1986). "The Ability of Nash's Theory of Cooperative Games to Predict the Outcomes of Buyer-Seller Negotiations: A Dyad-Level Test," Management Science 32 (April), 480-496.

Rao, Vithala R., and Joel H. Steckel. (Forthcoming). "A Polarization Model for Describing Group Preferences," Journal of Consumer Research Forthcoming.

Steckel, Joel H. (1990), "Committee Decision Making in Organization: An Experimental Test of the Core," Decision Sciences 21 (Winter), 204-215.

Steckel, Joel H., Donald R. Lehmann, and Kim P. Corfman. (1988). "Estimating Probahilistic Choice Models from Sparse Data: A Method and Application to Groups," Psychological Bulletin 103 (January), 131-139.

Steckel, Joel H., and John O'Shaughnessey. (1989). "Towards a New Way to Measure Power: Applying Conjoint Analysis to Group Decision," Marketing Letters 1 (June), 37-46.

Webster, Frederick E. Jr., and Yoram J. Wind. (1972). Organizational Buying Behavior, Englewood Cliffs, NJ: Prentice-Hall. 